\title{
Thermal Stability of SiBCN Films
}

\author{
Naohiro Hayashi ${ }^{1)}$, Junho Choi ${ }^{1{ }^{*}}$, Tomohisa Kumagai ${ }^{1)}$, Takahisa Kato ${ }^{1)}$, Masahiro Kawaguchi ${ }^{2)}$, \\ Setsuo $\mathrm{Nakao}^{3)}$ and Masami Ikeyama ${ }^{3)}$ \\ ${ }^{1)}$ Department of Mechanical Engineering, The University of Tokyo \\ 7-3-1 Hongo, Bunkyo-ku, Tokyo 113-8656, Japan \\ ${ }^{2}$ Advanced Material Processing Group, Tokyo Metropolitan Industrial Technology Research Institute \\ 3-13-10 Nishigaoka, Kita-ku, Tokyo 113-8586, Japan \\ ${ }^{3)}$ National Institute of Advanced Industrial Science and Technology (AIST) \\ 2266-98 Anagahora, Shimoshidami, Moriyama-ku, Nagoya, Aichi 463-8560, Japan \\ *Corresponding author: choi@mech.t.u-tokyo.ac.jp \\ ( Manuscript received 24 June 2008; accepted 12 August 2008; published 15 October 2008 ) \\ ( Presented at JAST Tribology Conference in Tokyo, May 2008 )
}

\begin{abstract}
Silicon-Boron-Carbon-Nitride (SiBCN) thin films were deposited on Si (100) substrates by ECR-type ion beam sputtering at a substrate temperature of $200{ }^{\circ} \mathrm{C}$, and thermal stability of SiBCN films were investigated at $600{ }^{\circ} \mathrm{C}, 700{ }^{\circ} \mathrm{C}$ and $800{ }^{\circ} \mathrm{C}$ in air. A composed Si-B-C (Si plate and $\mathrm{B}_{4} \mathrm{C}$ target) target was used for the film deposition. The composition and chemical bonding structure of the prepared films were investigated by $\mathrm{X}$-ray photoelectron spectroscopy and Fourier transform infrared spectrometer. Si-N bonds increased with increasing silicon content. Surface roughness of SiBCN films decreased with increasing Si content. Hardness of SiBCN films exhibited up to $22 \mathrm{GPa}$ with increasing silicon content. SiBCN films showed no changes in chemical bonds after heating at $600{ }^{\circ} \mathrm{C}$. Even after heating at $700{ }^{\circ} \mathrm{C}$, SiBCN films maintained relatively high hardness, whereas hardness of SiBCN films was quietly reduced after heating at $800{ }^{\circ} \mathrm{C}$. Thermal stability of SiBCN films was improved with increasing Si content.
\end{abstract}

Keywords: Silicon-Boron-Carbon-Nitride ( $\mathrm{SiBCN})$, ECR sputtering, thermal stability, oxidation resistance

\section{Introduction}

Si-B-C-N ceramics have attracted a great deal of interest due to their exceptional high temperature stability and oxidation resistance ${ }^{1-6)}$. This ceramics withstand temperatures up to $2000{ }^{\circ} \mathrm{C}$ in argon atmosphere ${ }^{3)}$, and show the high oxidation protection up to $1000{ }^{\circ} \mathrm{C}^{1,6)}$. In the field of ceramics, Si-C-N materials were researched as material with useful properties, such as high hardness, wide band gap characteristics, a wide optical transparency window and high temperature oxidation resistance. Recently, it has been reported that the addition of proper amount of boron in the Si-C-N ceramics leads to the great increases of high temperature stability and oxidation resistance ${ }^{3)}$. These effects in Si-B-C-N ceramics are possibly explained by the production of a turbostratic $\mathrm{BN}$ phase. A turbostratic $\mathrm{BN}$ phase makes local nitrogen pressure and shift decomposition reactions of $\mathrm{Si}_{3} \mathrm{~N}_{4}$. In addition to these high temperature properties, it has been reported that bulk Si-B-C-N system has features of high hardness up to $47 \mathrm{GPa}^{9}$, low compressive stress below $1.8 \mathrm{GPa}^{9}$, good adherence ${ }^{8)}$, transparency in visible spectra or controllable electrical conductivity ${ }^{1)}$. Thus, combining the elements silicon, boron, carbon and nitrogen in an amorphous network has resulted in ceramics with superior properties compared to other systems. This combination of properties is well suitable for coating technologies. This can provide the superior coating material in high temperature condition to the conventional material. On the other hand, DLC (diamond-like carbon) thin films have been applied to many fields for coating material. However, DLC films are greatly oxidized over $300{ }^{\circ} \mathrm{C}$ and their mechanical properties degrade. SiBCN thin films are expected to be applied to high temperature applications, such as the protective coating for molds for aluminum, which is used over $500{ }^{\circ} \mathrm{C}$. Vlček et al. provided results for mechanical properties and oxidation resistance of SiBCN films prepared by RF magnetron sputtering ${ }^{1)}$. In that paper, $\mathrm{SiBCN}$ films showed high thermal stability and useful mechanical properties. However, up to now, properties of SiBCN films have not revealed sufficiently and no effort has been made to obtain the SiBCN films by ion beam sputtering to investigate properties of these 


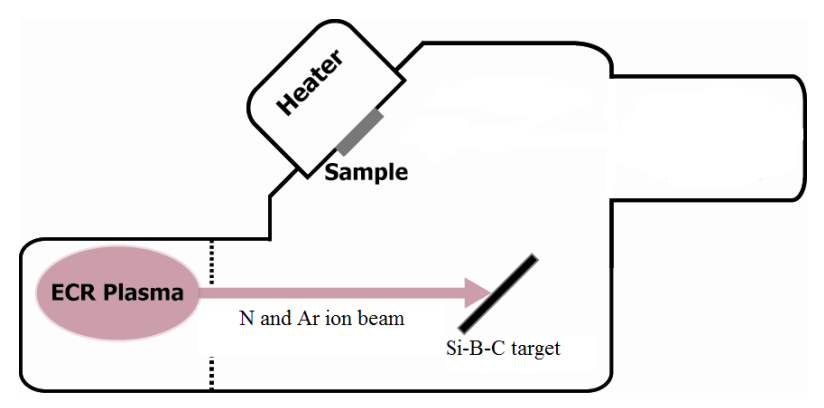

Fig. 1 Schematic diagram of ECR-type ion beam sputtering system used in the study

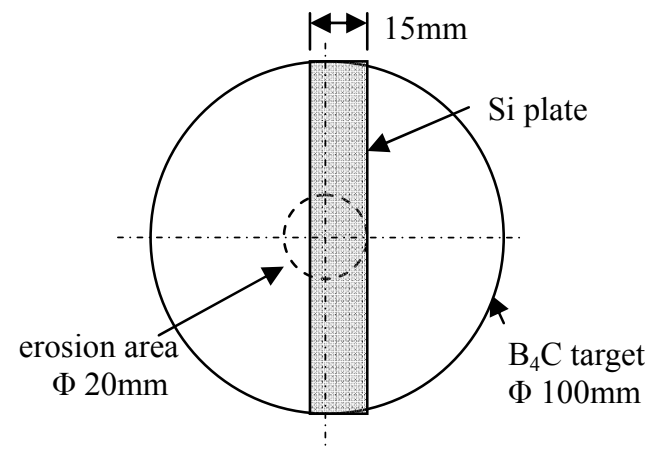

Fig. 2 Schematic of Si-B-C target

films. Contrary to some other techniques such as Chemical Vapor Deposition, ion beam sputtering can make films not to use hydrogen containing precursors and provide high adherence to substrates. Therefore, the improvement of oxidation resistance is expected.

In this work, we systematically investigated thermal stability of SiBCN films prepared by ECR-type ion beam sputtering using a composed Si-B-C (Si plate and $\mathrm{B}_{4} \mathrm{C}$ target) target in constant nitrogen-argon gas mixture. We varied the silicon fraction in the target erosion area in order to obtain $\mathrm{SiBCN}$ films with different $\mathrm{Si}$ contents. Thermal stability is evaluated by chemical bonding structure before and after heating at temperatures of 600,700 and $800{ }^{\circ} \mathrm{C}$. Also, Boron-Carbon-Nitride (BCN) films were prepared by the same sputtering system for comparison.

\section{Experimental details}

The SiBCN films on $\mathrm{Si}$ (100) substrates were prepared by ECR-type ion beam sputtering system using a Si-B-C target. The Si-B-C target was composed by $\mathrm{Si}$ plate and $\mathrm{B}_{4} \mathrm{C}$ target. Fig. 1 and Fig. 2 show schematically ECR-type ion beam sputtering system and composed Si-B-C target used for film deposition. The $\mathrm{B}_{4} \mathrm{C}$ target erosion area was partially covered with $\mathrm{Si}$ plate and the silicon content in the films was controlled by adjusting the coverage area of silicon plate. Before the film deposition, the target was sputtered-cleaned using $\mathrm{Ar}^{+}$ion. The nitrogen-argon gas mixture $\left(\mathrm{N}_{2}: 0.60\right.$ $\mathrm{sccm}$, Ar : $0.40 \mathrm{sccm}$ ) was used as sputtering gas. The base pressure of deposition chamber was lower than $1.0 \times 10^{-3} \mathrm{~Pa}$ and the deposition pressure was $2.0 \times 10^{-2} \mathrm{~Pa}$. The microwave power and acceleration voltage were $100 \mathrm{~W}$ and $2000 \mathrm{~V}$, respectively. All the depositions were performed at a substrate temperature of $200{ }^{\circ} \mathrm{C}$ to remove contaminations on the surface and increase adhesion strength between film and substrate. We also prepared $\mathrm{BCN}$ films using $\mathrm{B}_{4} \mathrm{C}$ target for comparison. The thickness of all the films was about $350 \mathrm{~nm}$. The elemental composition of the films was determined by X-ray photoelectron spectroscopy. Before XPS measurements, the films were sputtered by $4 \mathrm{kV}-\mathrm{Ar}^{+}$ ions for $120 \mathrm{~s}$ to remove the impurities on the surface. The chemical bonding structure was investigated by Fourier transform infrared spectrometer. The spectra were recorded in absorbance mode in the wavenumber range of $400-2400 \mathrm{~cm}^{-1}$. Roughness of SiBCN films was investigated by using atomic force microscopy before and after heat treatment. The scanning area and scanning speed were $10 \mu \mathrm{m}$ and $0.5 \mathrm{~Hz}$, respectively. Nanoindentation measurements were carried out, using a Berkovich-typed diamond indentor. The maximum load was $500 \mu \mathrm{N}$. Hardness values were obtained from the analysis of the unloading branch of the load-penetration curve. All the samples were annealed at temperatures 600,700 and $800{ }^{\circ} \mathrm{C}$ in air for $30 \mathrm{~min}$. These properties were investigated before and after heating.

\section{Results and discussions}

\subsection{Elemental composition of SiBCN films}

The elemental composition of the films is shown in Table 1. Nitrogen contents are almost constant and Si contents gradually increase due to increase of Si fraction in the target erosion area. It is reported that $\mathrm{CN}_{\mathrm{x}}$ film has a limit of $\mathrm{N}$ content in the film below approximately $35 \%$, and the increase of $\mathrm{Si}$ content increases the $\mathrm{N}$ content in SiBCN films. In the present films, $\mathrm{N}$ contents are almost constant though $\mathrm{Si}$ contents are changed. It is considered that content of incorporated $\mathrm{N}$ atoms is reached a maximum value in the prepared films. Boron contents are relatively high, whereas carbon contents are relatively low due to use of $\mathrm{B}_{4} \mathrm{C}$ target. The ratio of $\mathrm{B} / \mathrm{C}$ is about 3.5 in all samples.

Table 1 Atomic concentration (at.\%) of SiBCN films

\begin{tabular}{lllll}
\hline Samples & $\mathrm{B}$ & $\mathrm{C}$ & $\mathrm{N}$ & $\mathrm{Si}$ \\
\hline SiBCN5 & 31.4 & 10.8 & 30.7 & 27.1 \\
SiBCN4 & 37.9 & 7.4 & 31.7 & 23.0 \\
SiBCN3 & 36.4 & 9.8 & 34.0 & 19.8 \\
SiBCN2 & 38.9 & 11.7 & 33.1 & 16.2 \\
SiBCN1 & 42.7 & 12.4 & 33.0 & 12.0 \\
BCN & 55.6 & 12.7 & 31.7 & - \\
\hline
\end{tabular}




\subsection{Influence of heat treatment on chemical bonding}

FTIR spectra of films before heating are shown in Fig. 3(a). Two broad absorption bands are observed. One band is approximately centered at $1300 \mathrm{~cm}^{-1}$, which is correspondent to $\mathrm{C}-\mathrm{N}\left(\mathrm{sp}^{3}\right)$ bonds. This broad band includes at shoulder the peak of $\mathrm{h}-\mathrm{BN}$ bonds (1400 $\left.\mathrm{cm}^{-1}\right)$ and B-C bonds $\left(1170 \mathrm{~cm}^{-1}\right)$. The peak of double bonds of carbon is not observed around $1600 \mathrm{~cm}^{-1}$ in these films. The other broad absorption band is approximately centered at $950 \mathrm{~cm}^{-1}$, which is correspondent to $\mathrm{Si}-\mathrm{N}$ bonds. Higher silicon content results in increasing of $\mathrm{Si}-\mathrm{N}$ bonds and decreasing of $\mathrm{C}-\mathrm{N}$ bonds. Si and $\mathrm{C}$ mainly make single covalent bonds with $\mathrm{N}$ in these films. $\mathrm{N}$ is combined with all elements from a high affinity of $\mathrm{N}$ for $\mathrm{Si}, \mathrm{B}$ and $\mathrm{C}$. On the other hands, BCN film shows one broad absorption peak including B-C, C-N and h-BN bonds. C-N bonds are dominant in BCN film. Fig. 3(b) shows FTIR spectra of SiBCN and BCN films after heating at $600{ }^{\circ} \mathrm{C}$. SiBCN films show no changes of chemical bonds, whereas chemical bonds of BCN films are considerably changed.

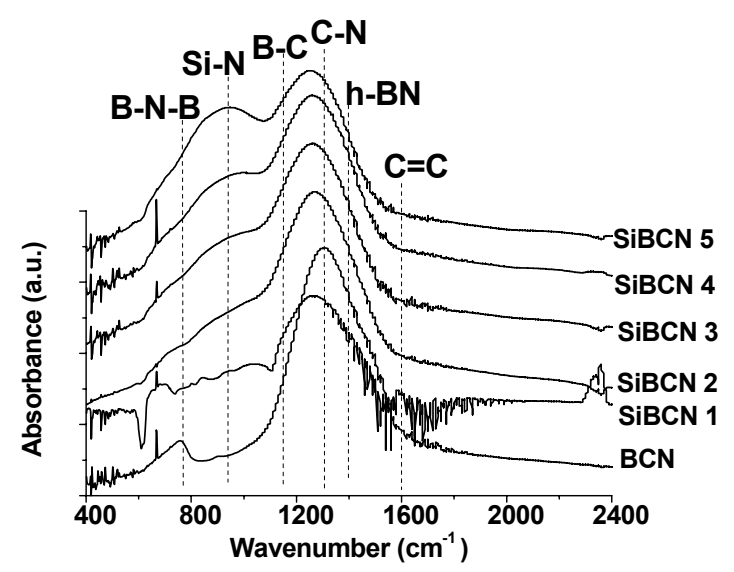

(a)

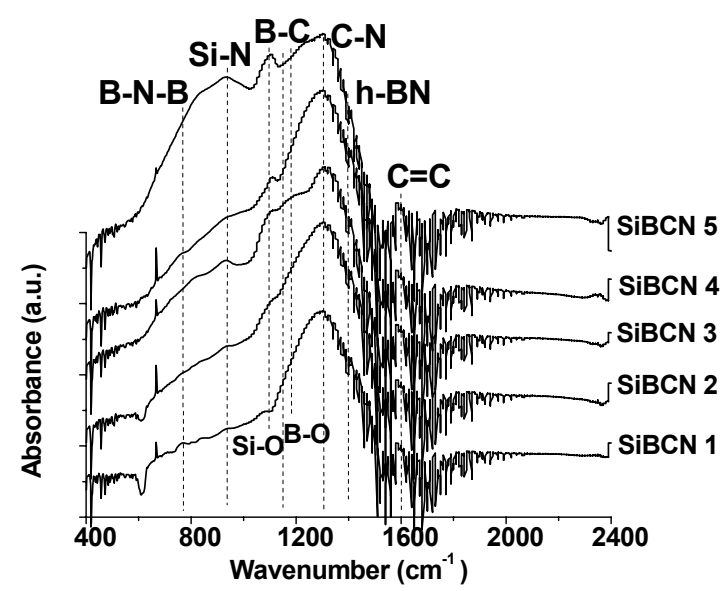

(c)
In the BCN films, only B-O bonds $\left(1190 \mathrm{~cm}^{-1}\right)$ and h-BN bonds are observed on the substrates. The SiBCN films show their high thermal stability and oxidation resistance at $600{ }^{\circ} \mathrm{C}$. This is probably caused by inactivation of carbon due to silicon incorporation and increase of thermally stable Si-N bonds. Thermal stability of Si-N bonds in bulk Si-B-C-N ceramics is enhanced due to a turbostratic $\mathrm{BN}$ phase. It is known that these $\mathrm{BN}$ phases take in $\mathrm{Si}_{3} \mathrm{~N}_{4}$ structures and this leads to restraining the decomposition of $\mathrm{Si}_{3} \mathrm{~N}_{4}$ : $\mathrm{Si}_{3} \mathrm{~N}_{4}+3 \mathrm{C} \rightarrow 3 \mathrm{SiC}+2 \mathrm{~N}_{2}$. A turbostratic $\mathrm{BN}$ phase in bulk ceramics grows at temperature range of $1000-1500{ }^{\circ} \mathrm{C}$, and the combinations of $\mathrm{B}$ and $\mathrm{N}$ in these thin films are supposed to form into turbostratic phase. Fig. 3(c) shows FTIR spectra after heating at $700{ }^{\circ} \mathrm{C}$. Changes of chemical bonds are observed. In particular, the small peak of Si-O bonds $\left(1070 \mathrm{~cm}^{-1}\right)$ becomes clear. h-BN bonds, which have high thermal stability up to $900{ }^{\circ} \mathrm{C}$, are unaffected by heating. Fig. 3(d) shows FTIR spectra after heating at $800{ }^{\circ} \mathrm{C}$. The peak of $\mathrm{Si}-\mathrm{O}$ bond is observed more sharply. SiBCN films are oxidized

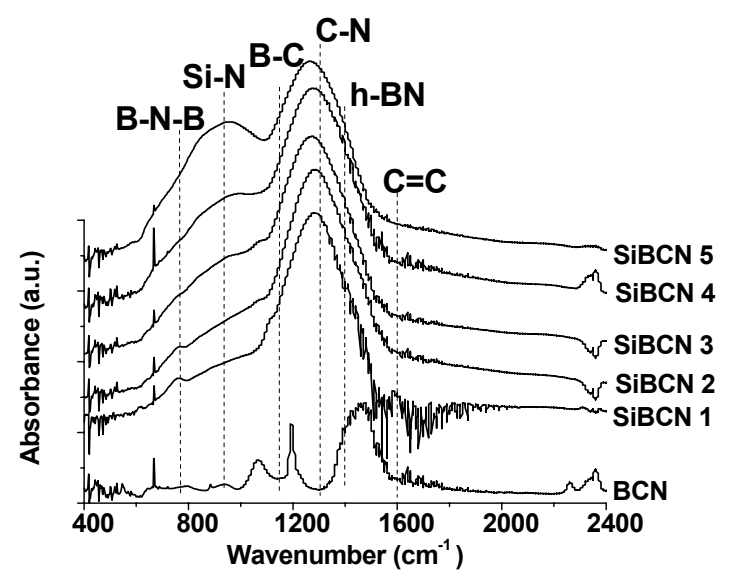

(b)

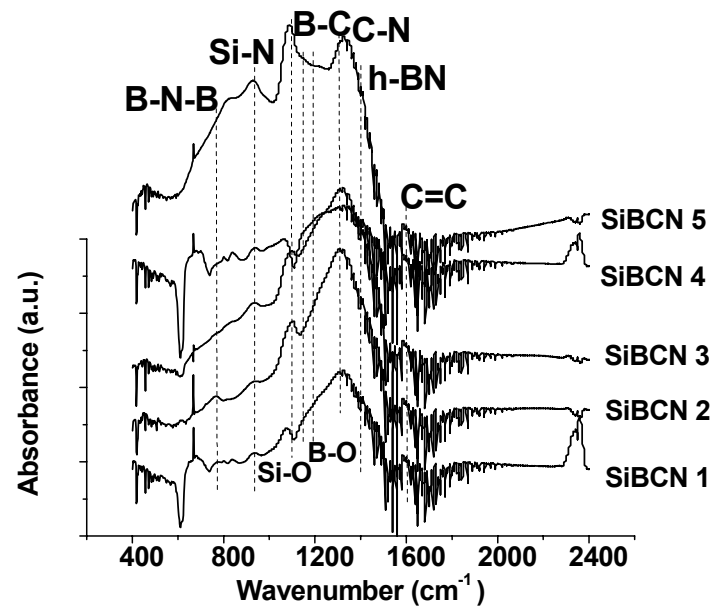

(d)

Fig. 3 FTIR spectra of SiBCN films before heating (a), and after heating at $600{ }^{\circ} \mathrm{C}$ (b), $700{ }^{\circ} \mathrm{C}$ (c) and $800{ }^{\circ} \mathrm{C}(\mathrm{d})$ 


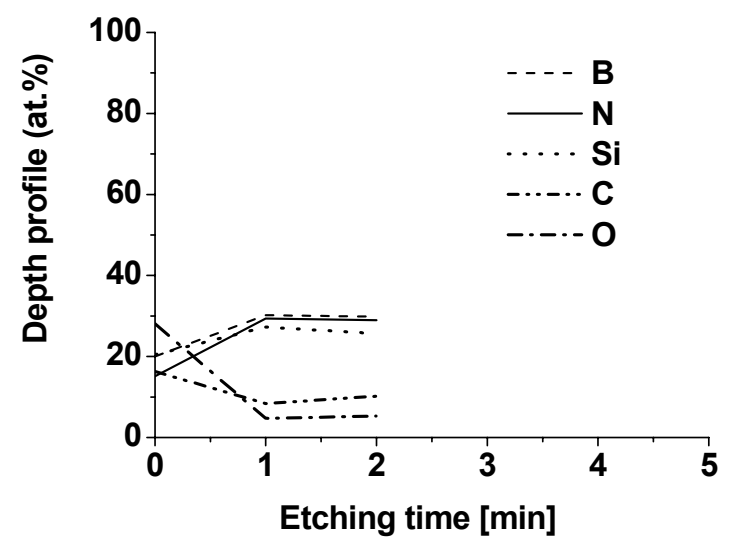

(a)

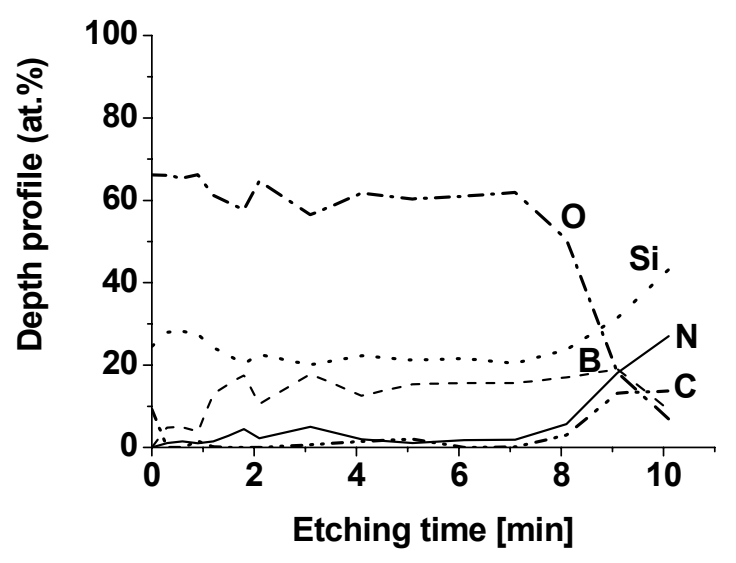

(b)

Fig. 4 Depth profiles of SiBCN5 (a) before heating and (b) after heating at $700{ }^{\circ} \mathrm{C}$

higher than $700{ }^{\circ} \mathrm{C}$. Baldus et al. described that the formation of a complex $\mathrm{BN}(\mathrm{O})-\mathrm{SiO}_{2}$ double layer was observed in Si-B-C-N ceramics due to oxidation at 1000 ${ }^{\circ} \mathrm{C}^{4)}$. Although oxide layer may protect films from further oxidation, hardness values were quite reduced (see Fig. 5).

Fig. 4 shows the depth profiles of SiBCN5 sample before and after heating at $700{ }^{\circ} \mathrm{C}$. The etching rate is about $12 \mathrm{~nm} / \mathrm{min}$. Silicon and boron oxides are observed on the surface of SiBCN film. The thickness of the oxide layer is about $100 \mathrm{~nm}$ after heating at $700{ }^{\circ} \mathrm{C}$.

\subsection{Influence of heat treatment on the hardness}

Fig. 5 shows changes of hardness before and after heating in air. The hardness gradually increases as $\mathrm{Si}$ contents increase in the films. SiBCN5 sample exhibits high hardness of $22 \mathrm{GPa}$, which is comparable to that of DLC film. The hardness of BCN film is $9 \mathrm{GPa}$. The great improvement of hardness of SiBCN films compared to $\mathrm{BCN}$ films is explained by increasing of $\mathrm{Si}-\mathrm{N}$ bonds due to Si incorporation. DLC films used in this study were prepared by the same ion beam sputtering system. It has been reported that the elements

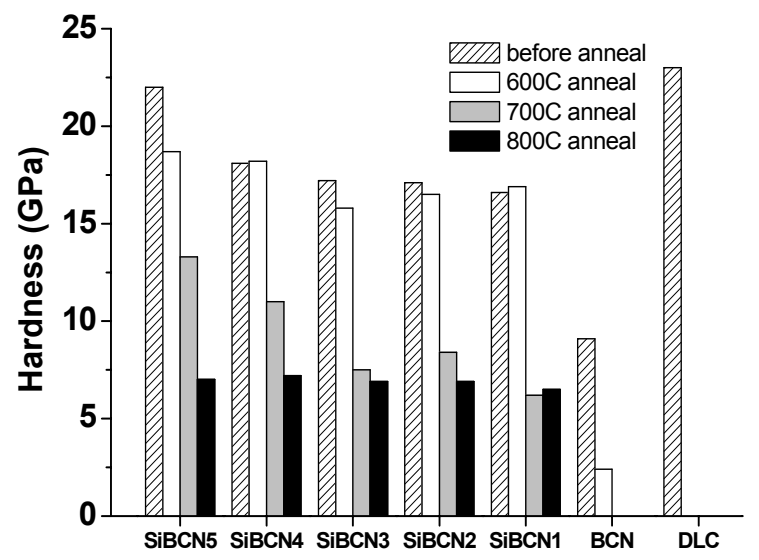

Fig. 5 Hardness changes after heating in air in the SiBCN films trend to have high coordination number and denser networks ${ }^{5)}$. This leads to the high hardness of materials. After heating at $600{ }^{\circ} \mathrm{C}$, SiBCN films were no reduction in hardness value, whereas hardness of $\mathrm{BCN}$ films quite decreased due to heating at $600{ }^{\circ} \mathrm{C}$.

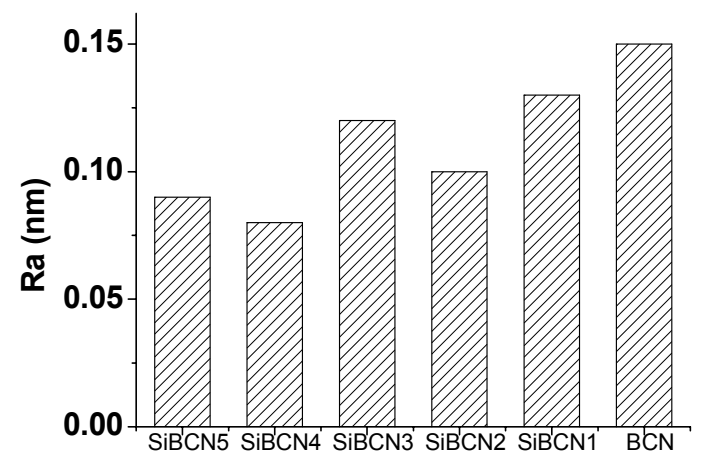

Fig. 6 Roughness of SiBCN films

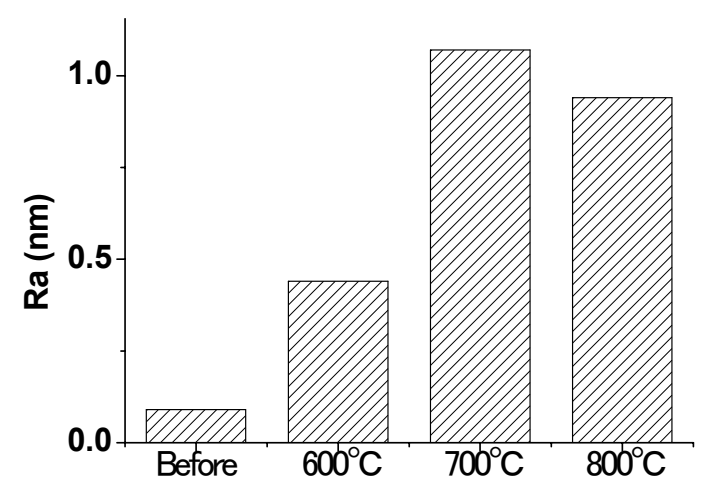

Fig. 7 Roughness change of SiBCN5 after heating 
3.4. Influence of heat treatment on the surface roughness

Fig. 6 shows arithmetic mean roughness of SiBCN films. The roughness of SiBCN film is very small and has a tendency to decrease with increasing $\mathrm{Si}$ content. Denser network due to $\mathrm{Si}$ incorporation probably results in the smooth surface. Fig. 7 shows the roughness change of SiBCN5 after heat treatment. It is observed that the surface roughness increases with increasing temperature of heat treatment due to the oxidation of film. The friction tests are now in progress.

\section{Conclusions}

SiBCN films were deposited by ECR-type ion beam sputter using a Si-B-C target and nitrogen-argon mixture as a sputter gas, and thermal stability of the films was investigated. The results obtained are summarized as follows:

(1) The SiBCN films exhibit high hardness up to 22 $\mathrm{GPa}$, which is comparable to that of DLC films. SiBCN films show very small roughness about 0.1 $\mathrm{nm}$.

(2) The SiBCN films show high thermal stability up to $700{ }^{\circ} \mathrm{C}$ and these thermal stability trends to increase with increasing Si content.

\section{References}

[1] Vlček, J., Potocký, Š., Č́ížek, J., Houška, J., Kormunda, M., Zeman, P., Peřina, V., Zemek, J., Setsuhara, Y. and Konuma, S., "Reactive Magnetron Sputtering of Hard Si-B-C-N Films with a High-Temperature Oxidation Resistance," J. Vac. Sci. Technol. A, 23, 6, 2005, 1513-1522.
[2] Hegemann, D., Riedel, R. and Oehr, C., "PACVD-Derived Thin Films in the System Si-B-C-N," Chem. Vap. Deposition, 5, 1999, 61-65.

[3] Müller, A., Gerstel, P., Weinmann, M. and Bill, J., Aldinger, F., "Correlation of Boron Content and High Temperature Stability in Si-B-C-N Ceramics," J. Euro. Ceram. Soc., 20, 2000, 2655-2659.

[4] Baldus, H. P. and Passing, G., "Studies on SiBN(C)-Ceramics: Oxidation- and Crystallization Behavior Lead the Way to Applications," Mater. Res. Soc. Symp. Proc., 346, 1994, 617-622.

[5] Houška, J., Vlček, J., Hřeben, S., Bilek, M. M. M. and Mckenzie, D. R., "Effect of B and the $\mathrm{Si} / \mathrm{C}$ Ratio on High-Temperature Stability of Si-B-C-N Materials," Europhysics Letters, 76, 3, 2006, 512-518.

[6] Butchereit, E. and Nickle, K. G., "Precursor-Derived Si-B-C-N Ceramics: Oxidation Kinetics," J. Am. Ceram. Soc., 84, 10, 2001, 2184-2188.

[7] Dekempeneer, E. H. A., Meneve, J., Kuypers, S. and Smeets, J., "Tribological Properties of R.F. PACVD Amorphous B-N-C Coatings," Thin Solid Films, 281-282, 1996, 331-333.

[8] Baldus, H. P. and Jansen, M., "Novel High Performance Ceramics - Amorphous Inorganic Networks from Molecular Precursors," Angew. Chem. Int. Ed. Engl., 36, 1997, 328-343.

[9] Jüngermann, H. and Jansen, M., "Synthesis of an Extremely Stable Ceramic in the System $\mathrm{Si} / \mathrm{B} / \mathrm{C} / \mathrm{N}$ Using 1-(Trichlorosilyl)-1-(Dichloroboryl) Ethane as a Single-Source Precursor," Mater. Res. Innovat., 2, 1999, 200-206. 